\title{
Mediação informacional no contexto universidade-sociedade-inovação: potencialidades, contradições e desafios
}

Anderson Fabian Ferreira Higino

Professor do CEFET-MG; especialista em Ensino de Física pela UFMG; mestre em Educação Tecnológica pelo CEFET-MG; doutorando em Ciência da Informação pelo PPGCI/UFMG; integrante do Programa de Ensino, Pesquisa e Extensão A tela e o texto (FALE/UFMG).

Alcenir Soares dos Reis

Professora adjunta do PPGCI/ECI/UFMG.

Lígia Maria Moreira Dumont

Professora titular e atual diretora da Escola de Ciência da Informação da UFMG. ${ }^{i}$

Maria Antonieta Pereira

Professora aposentada da Faculdade de Letras da UFMG.

Discute-se a relação entre universidade e inovação, focalizando formas de mediação que contemplem a responsabilidade social dessa instituição. Abordagens de ecologia dos saberes, teorias de rede e pensamento complexo articulam-se a elementos teóricos sobre educação, cultura, leitura e cidadania, para explicitar possibilidades inovadoras em três projetos com diretriz social ligados à UFMG. Especialmente no atual contexto das tecnologias de informação e comunicação, as potencialidades e contradições aqui destacadas apontam como desafio a própria inovação institucional da universidade brasileira.

Palavras-chave: Relação universidade-inovação; Mediação informacional; Responsabilidade social 


\title{
Informational mediation in the university-society-innovation context: potentialities, contradictions and challenges
}

\begin{abstract}
this article discusses the relation between university and innovation focusing on forms of mediation that address the social responsibility of this institution. The discussion is carried out by combining approaches from the ecology of knowledges, network theories and complex thinking with theoretical elements on education, culture, reading and citizenship. It highlights the innovation potential of three social-focused projects related to the Federal University of Minas Gerais, Brazil. Especially as they relate to the present context of information and communication technologies, the potentialities and contradictions brought to light indicate that institutional innovation itself is a major challenge to Brazilian university.
\end{abstract}

Keywords: University-innovation relation; Informational mediation; Social responsibility

\section{Descobrindo trilhas...}

O campo das mediações tecnológicas e simbólicas referentes à interação com a informação e o conhecimento é hoje fortemente marcado, dentre outros fatores, pela presença de produtos, discursos e formas de poder ligados ao movimento mundial pela inovação tecnológica, que exerce uma pressão especialmente intensa no contexto das tecnologias de informação e comunicação. Importa, por isso, construir pontes teóricas entre a pesquisa sobre mediações, em sua dimensão epistemológica, e o campo da reflexão crítica e da ação política voltadas a evitar distorções de ordem institucional e econômica que decorrem dessa pressão. Uma das pontes possíveis encontra-se no caminho da discussão referente às consequências, para a universidade, da pura adesão ao discurso da inovação. Como parte do meio acadêmico, as instituições ligadas à Ciência da Informação ficam também sujeitas, de algum modo, a essas pressões e consequências. Para prosseguir nas conexões, tomemos essa trilha...

Chauí (2003) discute alguns aspectos do assunto a partir da distinção entre duas formas de prática social: de um lado, a organização, definida por sua particularidade, instrumentalidade, competitividade e caráter autorreferenciado e não crítico; de outro lado, a instituição, definida por sua universalidade, autonomia e caráter sociorreferenciado e crítico-reflexivo. No Brasil, a reforma política da década de 1990, ao 
estabelecer a educação como serviço não exclusivo do Estado, converteu a universidade de instituição social republicana e democrática em organização social prestadora de serviços. Isso abriu portas a enormes pressões mercadológicas sobre a instituição universitária. Nesse contexto, a pesquisa tende a afastar-se de um caráter social, tornando-se predominantemente organizacional, ou operacional. Nessa perspectiva, a universidade passa a atuar num cenário competitivo no qual se distorcem fortemente a docência e a formação, confundidas com transmissão rápida e com treinamento, bem como a pesquisa e seu financiamento, que se transmutam em componentes da própria lógica de produção e acumulação capitalista.

Mesmo com uma alusão apenas ocasional à inovação, Chauí (2003) faz alertas valiosos para a discussão a esse respeito. O primeiro volta-se aos critérios quantitativos atualmente impostos à avaliação da produção acadêmica: esse processo gera uma visão enganosa de "inovação", que produz novidades e modas sem, de fato, revolucionar estruturas teóricocientíficas de modo crítico-reflexivo e socialmente relevante. Existe ainda o risco de a adesão aos critérios tornar-se submissão e progressiva dependência em relação a perversos mecanismos desmobilizadores e deslegitimadores da própria instituição universitária. O segundo alerta desvela, por trás das rápidas mudanças dessa "era da incerteza" que hoje vivemos, a frenética destruição econômico-social de referenciais de espaço e tempo cujo sentido era dado pela percepção cotidiana e pelas disciplinas humanísticas. Muito mais que incerteza, tal processo gera insegurança, a qual produz, em vez de conhecimento e ação inovadora, medo, paralisia, submissão ao instituído, recusa da crítica, conservadorismo e autoritarismo.

Ao discutir desafios e possibilidades para uma reforma democrática e emancipatória da universidade, também Santos (2004a) contribui para a compreensão das ambivalências que assume a adesão ao movimento pela inovação tecnológica, bem como da pertinência de incorporar o cuidado com a reflexão crítica e a ação política que aí deve estar presente. Num cenário de descapitalização da universidade pública e de expansão transnacional do mercado universitário, sob a égide do pensamento neoliberal, uma participação entusiástica no admirável mundo novo da inovação tecnológica pode implicar a submissão a uma lógica que desmobiliza o potencial político e a função social, aspectos dos mais importantes para a legitimação da universidade. Apesar desse risco, no entanto, a pretensão de recusar-se totalmente a participar é hoje uma perspectiva ilusória, de consequências ainda mais graves. A solução do dilema parece estar em saber como conduzir a participação e que limites impor.

\section{Entrelinhas, contrapontos}

A revista UFMG Diversa fornece exemplos eloquentes do caráter atual e necessário dessa discussão. O número 10 da publicação (UFMG, 
2006) toma a inovação como tema, em artigos que refletem um posicionamento institucional bastante entusiástico quanto ao envolvimento da universidade com a visão mercadológica desse processo. Deve-se reconhecer que a entrevista de abertura e alguns dos artigos toquem em questões ligadas ao interesse social, abordem noções como tecnologia social e focalizem iniciativas voltadas para a saúde pública e a inclusão de portadores de necessidades especiais. No entanto, a tônica geral é bem outra. Prevalece um discurso que dá claro destaque a pesquisas e abordagens compatíveis com a lógica de mercado, apontando ainda muito timidamente para a construção de um equilíbrio, tanto no plano crítico-reflexivo quanto no das políticas e dos programas, entre a dimensão técnico-econômica e a da responsabilidade social.

O artigo sobre a Lei de Inovação Tecnológica, assinado por integrantes do Setor de Licitações e Contratos da Procuradoria Federal da Universidade, exibe um tom laudatório que não abre qualquer espaço à reflexão sobre pontos nevrálgicos do debate instigado pelos aspectos polêmicos do instrumento legal - conforme aponta Mancebo (2004). Os artigos sobre patentes, propriedade intelectual, incubadoras, empreendedorismo e sistemas nacionais de inovação, quando chegam a sinalizar alguma questão relacionada a benefício social ou interesse público, fazem-no de modo veladamente equivocado ou francamente insatisfatório. Num dos casos, é meramente citado o fracasso na tentativa de transferência tecnológica para um laboratório público de farmacologia. Porém, essa alusão, de evidente conotação crítica, longe de integrar-se a uma discussão consistente, é feita de forma isolada, assumindo o tom de um juízo depreciativo cuja gratuidade não pode prestar bom serviço sequer à imagem do emissor e da publicação. Noutros casos, as referências ao interesse público são diretamente acopladas à lógica de mercado. Em muitas linhas e entrelinhas, soa um tanto forçada a "rima", que se apresenta como virtuosa, entre o bem social e a parceria com a indústria.

A publicação em análise cumpre um papel de vitrine institucional, voltando-se à divulgação da universidade perante a sociedade. Em não se tratando de um espaço teórico-crítico, é até possível entender o fato de questões sensíveis não receberem ali um tratamento aprofundado. Ainda assim, além do pequeno espaço dedicado à discussão do interesse social e do benefício público, causa estranheza a virtual ausência de registro ao menos sobre que existem questões a debater e pontos a aprofundar para que se possa construir uma relação equilibrada da universidade com o meio produtivo, no cenário aberto pela Lei de Inovação e por outras configurações que o movimento da inovação tem assumido, dentro e fora da instituição.

Em dois do 16 artigos, sob a ótica de um conceito em construção, o tema tecnologias sociais é abordado por integrantes do Núcleo de Estudos sobre o Trabalho Humano (NESTH/UFMG). Esses textos trazem valiosos relatos de iniciativas inovadoras referentes à economia solidária e à inclusão social, tais como uma incubadora de projetos sociais, a 
perspectiva de parceria com o poder público em municípios da região metropolitana de Belo Horizonte e o planejamento de ações destinadas ao interior de Minas Gerais. Hoje, porém, é difícil avaliar que sequência tiveram tais projetos, que estavam em curso no ano de 2006 . Em visita à página do NESTH, ${ }^{\text {iii }}$ verifica-se que aquelas ligações com 0 interesse público remetem, agora, ao mundo misterioso dos "links quebrados". Vale questionar se essa falha informacional apresenta contrapartidas no mundo das decisões institucionais, que é a fonte da informação aqui analisada. Teriam sido também rompidos, no âmbito político, algumas das conexões que dariam base à realização dos planos e perspectivas divulgados naquela época? Na página eletrônica, um dos links quebrados, em especial, reitera, simbolicamente, o questionamento sobre os caminhos institucionais seguidos pela universidade: "quem somos"?...

Uma análise semelhante do número 17 da UFMG Diversa (agosto de 2009) reforça ainda mais a percepção aqui anotada. Na discussão sobre "cidades" apresentada na publicação, o tema da inovação é diretamente tratado num único artigo, por um viés marcadamente técnico-econômico, com uma apresentação entusiasmada das perspectivas ligadas à implantação do parque tecnológico $\mathrm{BH}$-Tec por um consórcio público que inclui a UFMG (CUNHA; SANTOS, 2009). Mesmo reconhecendo a importância dessa iniciativa e o valor da análise feita pelos autores, somos levados a perguntar pela discussão sobre as tecnologias e inovações de cunho social tão fortemente demandas pelos conflitos e tensões do espaço urbano. Evidencia-se, novamente, a prevalência de um ponto de vista institucional que associa a discussão sobre tecnologia e inovação diretamente ao modelo hegemônico, ligado ao mercado, e relega a segundo plano questões relacionadas ao bem público e ao interesse social.

A própria função de "vitrine" da publicação faz ler, nessas edições, uma mensagem que vai além das linhas e letras, pois as entrelinhas articulam um padrão comunicacional. Numa vitrine, põe-se em destaque aquilo que deve chamar a atenção de quem por ela passa os olhos, ao mesmo tempo em que se exclui o que está "fora de moda" e procura-se disfarçar a presença, muitas vezes incômoda e invevitável, de algum detalhe que possa comprometer ou enfear o cenário. Desse ponto de vista, a postura institucional adesista à visão hegemônica de inovação fica duplamente exposta: pelo destaque do elogio e pela falta da crítica. Se aqui fazemos o contraponto, dando destaque à falta, é por pensarmos que o olhar crítico e vigilante é parte do trabalho árduo que levará a conquistar maior equilíbrio entre as múltiplas e delicadas dimensões dos desafios propostos por uma perspectiva mais ampla de inovação.

\section{Novos caminhos para as relações universidade- sociedade-inovação}

Nessa trilha, para além da comercialização do conhecimento, Santos (2004a) aponta o desafio epistemológico do confronto entre dois modelos: o conhecimento universitário - disciplinar; homogêneo-hierárquico; de 
produção socialmente descontextualizada e descomprometida - e o conhecimento pluriversitário - contextual; organizado com base na aplicação; partilhado por pesquisadores e utilizadores; transdisciplinar e heterogêneo, por envolver diálogo e confronto com outros conhecimentos; aberto, ao contemplar uma forma de produção baseada em cooperação, solidariedade e parcerias. O conhecimento pluriversitário compatibiliza-se com ambientes de grande interatividade e admite, além da interação universidade-indústria, parcerias não-mercantis, pluriétnicas e multiculturais, forçando o conhecimento científico ao confronto com outros saberes e a uma maior responsabilização social.

Nesse contexto epistemológico, Santos (2004a) discute a existência de duas pressões contrárias, que tendem a desestabilizar a institucionalidade atual da universidade. De um lado, a pressão hiperprivatística tende ao aumento da eficiência produtiva e à mercantilização do conhecimento, bem como à redução da responsabilidade social da universidade. De outro lado, a pressão hiperpublicista envolve particularmente a mídia, fragmenta o espaço público da universidade e força-o rumo a um espaço público mais amplo, marcado por confrontos mais heterogêneos e concepções mais exigentes de responsabilização social.

Santos (2004a) também assinala a estreita relação entre a universidade pública e o projeto de país, inclusive no partilhamento de um caráter elitista que deve ser criticado e reformulado, nos dois casos. $O$ Estado nacional encontra-se sob forte ataque neoliberal, padecendo de incapacidade política de responder adequadamente aos desafios que enfrenta. Também a universidade pública demonstra incapacidade epistemológica e desorientação social, vivendo uma crise de identidade que se estendeu ao próprio pensamento crítico e às concepções de espaço público, espremidos entre o isolamento nacionalista e uma globalização miniaturizante, distorsiva e opressora. Esse dilema corresponde ao pesado desafio que enfrentam os países periféricos e semiperiféricos: a necessidade de reinventar o projeto nacional. $O$ autor sugere um esforço de interação e colaboração que permita construir um cosmopolitismo crítico, como forma alternativa de globalização, em oposição ao movimento neoliberal. Além dessa perspectiva contra-hegemônica das relações internacionais, a visão de Santos (2004a) também possui implicações, no âmbito interno a cada nação, para lutas que envolvem indivíduos, coletividades diversas, movimentos sociais, organizações e instituições das sociedades civil e política.

Essas implicações são bem apreciadas à luz do modelo de Janete Azevedo (2004) para a construção de políticas públicas - originalmente proposto para o campo da educação, mas aplicável a áreas diversas. A construção de políticas públicas é vista como um processo complexo e multidimensional, que contempla dimensões cognitivas, instrumentais e normativas. O contexto é uma sociedade integrada por setores (transporte, educação, saúde etc.) que participam das definições políticas, visando principalmente a influenciar os rumos do desenvolvimento 
econômico nacional. Numa visão sucinta, essa participação se dá no domínio das práticas políticas (politics), levando à construção de programas de ação (policy), sob a influência do referencial normativo existente tanto no nível de toda a nação (global) quanto em cada setor (setorial). Esses referenciais baseiam-se nas representações sociais predominantes em cada setor, que estabelecem uma disputa intrassetorial pela hegemonia. Paralelamente, ocorrem disputas intersetoriais pelo uso dos recursos disponíveis no Estado para o atendimento de interesses setoriais específicos. A hegemonia intrassetorial permitirá influenciar mais significativamente a definição do conteúdo da solução política adotada. Nesse contexto, uma demanda que tiver enfrentado um processo de problematização mais consistente encontra-se em melhores condições para definir uma política pública específica.

Há uma significativa convergência desse modelo com a proposta de Santos (2004a) para a reconquista da legitimidade da instituição universitária: é necessário negociar um novo contrato político-social, a partir dos diversos contratos setoriais, aí incluído o educacional, em cujo âmbito os esforços devem se voltar para que a universidade seja considerada um bem público. Esse é o caminho para a universidade construir uma nova institucionalidade, integrando-se decididamente à luta por uma globalização contra-hegemônica. No tocante à ideia de inovação, os alertas creditados a Chauí (2003) possibilitam completar a seguinte perspectiva: para além da capciosa visão da inovação tecnológica mercantilizadora do conhecimento, é necessário buscar a própria inovação da institucionalidade universitária, lutando-se para que essa instituição se coloque a serviço de uma visão e de uma prática que signifiquem a reinvenção de sua responsabilidade social. Essa é a verdadeira inovação que se deve buscar: articulada com a história de cada país e cada povo; atenta a demandas sociais que encontram dificuldade em fazer-se ouvir em meio ao vozerio das lutas intrassetoriais e intersetoriais características do campo da ação política; ampliadora da lucidez crítica com que se veja a interação com o meio produtivo; não adesista aos modos e modas do mercado, mas sim voltada para um futuro de conquistas no campo da justiça social, em termos nacionais e internacionais. Mesmo cuidando de ater-se a suas especificidades institucionais, a universidade tem muito a fazer, no sentido desse desafio mais amplo, que não deixa de admitir a interação com o meio produtivo e o desenvolvimento da inovação tecnológica, mas exige claro posicionamento contrário à submissão ao mercado.

$\mathrm{Na}$ perspectiva do novo contrato social proposto por Santos (2004a), a universidade deve buscar alternativas consistentes com sua responsabilidade social em cada campo que a integra: ensino, pesquisa e extensão. No caso da pesquisa, ela deve se pautar por objetivos sociais amplos, de modo a, mesmo estabelecendo parcerias com empresas e organizações do setor produtivo, não alienar ao mercado a definição dos temas e programas. O desafio é buscar formas de associação universidade-indústria que signifiquem uma delicada articulação 
epistemológico-produtivo-social, permeável às demandas sociais, sobretudo as não-hegemônicas. Essa ampliação da responsabilidade social levará a universidade a reconquistar, em seu setor de atuação, a legitimidade e a hegemonia hoje tão fortemente ameaçadas.

Usando as categorias de análise indicadas por Santos (2004a), propomos uma representação gráfica (Figura 1) que, mesmo sendo de caráter preliminar, acreditamos possuir certo valor heurístico. O campo de tensões no qual se encontra inserida a universidade foi representado da seguinte forma: no eixo horizontal, a tensão entre os modelos universitário e pluriversitário de conhecimento; no eixo vertical, a tensão entre as pressões hiperprivatista e hiperpublicista. Com o auxílio desse espaço de representação, sintetizamos as discussões sobre o envolvimento com a inovação.

A figura oferece uma visão sintética de dois modos de inovação com os quais a universidade pode se envolver. O modo 1 de inovação acopla a instituição à transição do conhecimento universitário para o conhecimento pluriversitário num movimento que cede mais à pressão hiperprivatística do que a uma visão ampla da pluralidade de conhecimentos e muito mais do que às preocupações sociais abarcadas pela visão de publicização. Nesse caso, a pluralidade publicista passa ao largo do esforço inovador, que admite a pluralidade apenas na medida em que esta coadune com interesses financeiros, exigências de mercado e as outras formas que assuma a pressão privatística. Esse modo de inovação corresponde a uma adesão à lógica neoliberal de globalização econômica, criticada em nossa abordagem.

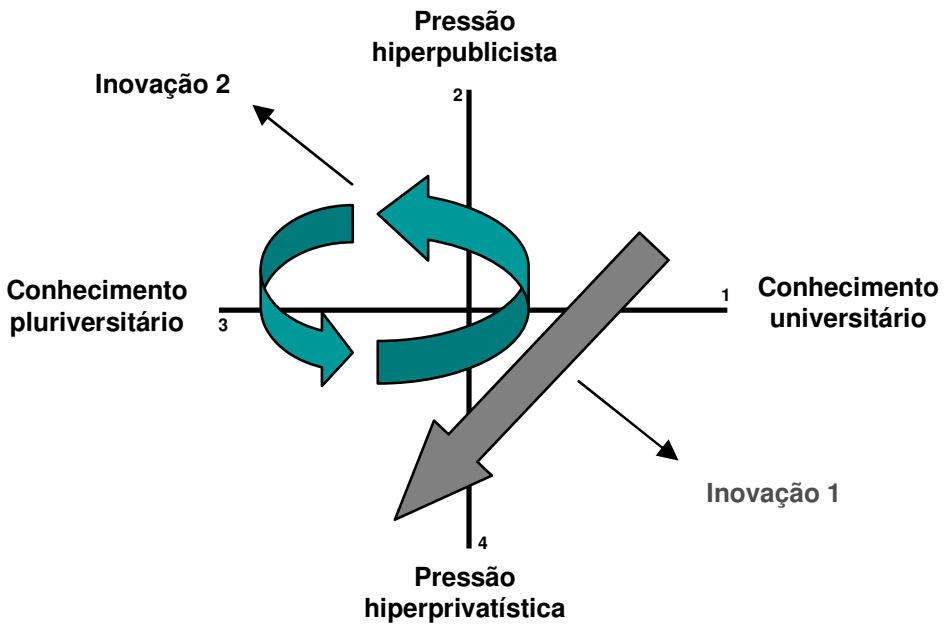

Figura 1 - Representação gráfica dos modos de inovação

(elaborada por Anderson Higino, com anuência dos demais autores)

O modo 2 de inovação envolve maior adesão à visão de pluralidade de conhecimentos que a universidade é desafiada a buscar, propiciando a compatibilidade com a contextualidade, a abertura, a porosidade e a permeabilidade componentes da noção de ecologia dos saberes, proposta por Santos (2004a, b). Além disso, o modo 2 cede mais à pressão publicista do que à privatista, ainda que admita diálogo equilibrado com 
esta e evite os excessos daquela. Assim, torna-se possível pensar numa produção de inovação que envolva, por exemplo, transparência e divulgação, mas não uma midiatização estimuladora de estrelismos pessoais ou organizacionais, e que equilibre uma comedida transigência com o capital nacional à cobrança da responsabilidade estatal, em termos de financiamento e desenvolvimento tecnológico.

Pelo potencial de equilibração e reequilibração não-linear e dialógica das dimensões categoriais destacadas, o modo $\mathbf{2}$ atende melhor às demandas apontadas em nossa discussão. Esse modo assinala uma perspectiva de inovação tecnológica que pressupõe a garantia de espaço para que se inove e renove a própria universidade, num necessário processo de reconstrução de sua institucionalidade atual. Ao ampliar as condições da universidade para assumir a responsabilidade social que the cabe, esse processo possibilita à instituição recobrar uma condição mais consistente de hegemonia, legitimidade e autonomia. Esse é o caminho para formas de atuação na vida nacional e no cenário mundial que permitam compatibilizar o desenvolvimento tecnológico e o benefício econômico com aspectos tais como participação política ativa, desenvolvimento da cidadania e inclusão social e cultural, dentre outros.

A seguir, são apresentados exemplos de três iniciativas de ensinopesquisa-extensão que têm por foco mediações e usos sociais da informação e do conhecimento e buscam efetivar ações que estejam em consonância com a discussão desenvolvida.

\section{Digital storytelling: enunciação e (re)construção da narrativa de vidaiv}

No eixo de discussão proposto, frente à preocupação de evidenciar o papel de responsabilidade social da universidade, em termos da inovação, é importante trazer para o debate a experiência de ensino e pesquisa com o uso da metodologia digital storytelling. Suas potencialidades metodológicas vêm do fato de possibilitar que o ator/narrador da própria história traga à tona questões intrínsecas do seu universo e possa colocar em contraponto os elementos de sua subjetividade com o contexto histórico-político no qual se encontra inserido.

É oportuno indicar que essa proposta é de autoria do professor Joseph Lambert, fundador do movimento internacional Digital Storytelling e diretor executivo do Center for Digital Storytelling (Centro de Histórias Digitais), localizado na Califórnia, EUA. ${ }^{\vee}$ O professor é internacionalmente reconhecido como especialista na aplicação, seja em mídia impressa ou digital, da abordagem desenvolvida por ele e seus colegas na década de 1990. A metodologia vem sendo adotada como parte do currículo de escolas e universidades e utilizada em pesquisas e projetos de mobilização social mediados por tecnologias, em diversas áreas do conhecimento, como história, computação, cinema, sociologia, antropologia e educação.

O repasse da metodologia é realizado por meio de seminários/oficinas de caráter intensivo, geralmente organizados como 
atividade de tempo integral e duração típica de três a quatro dias, com um mínimo de 12 horas, para turmas de 8 a 12 participantes. A proposta é criar, elaborar e produzir uma história digital com duração de três a cinco minutos. Na etapa de realização, os participantes primeiro montam e gravam narrativas de vida em primeira pessoa, além de coletar fotos, imagens, gravuras e músicas, para ilustrar seus trabalhos. Em seguida, usando um aplicativo computacional, realizam o trabalho de edição, contando com o auxílio de tutoriais e com o apoio da equipe responsável, para concretizar o processo metodológico da storytelling. Evidencia-se, assim, o objetivo principal da metodologia: oferecer ao sujeito um espaço de enunciação e narrativa. Ao realizar o exercício de contar sua história, o indivíduo refaz o percurso das próprias vivências e traz para a dimensão explícita as indagações, as angústias e as alegrias que constituem seu patrimônio enquanto ser.

A Escola de Ciência da Informação da UFMG (ECI/UFMG) recebeu a visita do professor Lambert em abril de 2006, ocasião em que foi implementado o curso digital storytelling. A análise e a avaliação dessa experiência levaram à opção de repassar a vivência e a aprendizagem da metodologia, por meio da oferta de oficinas ao público da instituição, com a introdução - em caráter complementar - da perspectiva dialógica de Freire (1988) e da visão de Boal (1975), referente ao teatro do oprimido. A realização das oficinas tornou evidente a importância de incorporar a metodologia no âmbito da ciência da informação.

Vale apontar que o desafio de reconstituir e narrar o vivido gera um mergulho que possibilita a compreensão do lugar histórico dos sujeitos nas tramas da realidade social, levando a apreender a ideia de que se acham imbricadas, nos processos narrativos, as dimensões da informação e do conhecimento. De fato, o autor da história vivencia que é necessário selecionar uma ótica, definir um ponto de vista e realizar recortes. Constrói-se, assim, pela análise e pela interpretação do vivido, um conhecimento crítico que evidencia as contradições presentes na interação entre 0 individual e o coletivo. Essa experiência permite aclarar as contradições que perpassam a experiência pessoal, tornando possível compreender a própria história, colocá-la em questão e usar as percepções resultantes desse processo como instrumento de ação.

A experiência que autoriza a narrativa aqui apresentada concretizouse por meio de três oficinas que tiveram como público alunos de graduação e pós-graduação e docentes da ECI/UFMG. Esse trabalho permitiu finalizar cerca de 40 vídeos, com duração de 2 a 5 minutos. Por meio da linguagem e dos temas propostos pelos vários autores, os vídeos trouxeram à tona a imbricada relação entre biografia e história, revelando distintas facetas da realidade social, com destaque para as relações de âmbito familiar, os desafios profissionais e o lugar do sujeito frente ao mundo. $O$ intenso envolvimento vivido nessa experiência fez perceber o grande potencial da metodologia para trabalhos referentes às mediações sociais da informação. Isso levou a incorporar, como desafio de pesquisa, a utilização da storytelling em comunidades da periferia de Belo Horizonte, 
elegendo-se a possibilidade de realizar oficinas com os adolescentes vinculados a programas sociais que prestam serviço à universidade, nas comunidades atendidas pelo Carro-Biblioteca da ECI/UFMG e no âmbito de projetos destinados à educação de jovens e adultos.

Em síntese, o contato com a digital storytelling trouxe o vislumbre de promissores caminhos para a inclusão de distintos públicos no uso das novas tecnologias de informação e comunicação. Essa metodologia é um importante instrumento para o registro e o compartilhamento da história e da memória, além de uma ferramenta de apreensão da realidade social capaz de ampliar possibilidades de crítica e questionamento da ordem vigente. Sob tal prisma, ela se presta a um consistente trabalho de mediação entre universidade e inovação, pela via da responsabilidade social.

\section{Carro-biblioteca: trajetos de formação de leitores- cidadãos}

A ciência da informação valoriza o indivíduo como sujeito construtor de significados, com base na vivência das situações sociais experimentadas ou anteriormente herdadas. Cada vez mais, o indivíduo é considerado agente na interação entre a informação recebida e seus próprios conceitos. Também é dada, hoje, maior ênfase ao enfoque direcionado aos usuários, em contínua interação com o meio e com outros indivíduos. Essas tendências podem ser contempladas pela perspectiva cognitiva, a qual, ao contrário do que afirmam alguns críticos, não leva a ciência da informação a perder de vista a dimensão social. As formulações contemporâneas reiteram, inclusive, que as pessoas, mesmo vivendo situações próprias, possuem formação coletiva, de sentido social. Assim, segundo esses estudos, os conceitos e sentidos usados nessas situações não são exclusivamente nossos, e sim construções sociais.

Tais estudos levam ainda a outras inquietações, que é necessário considerar. A perspectiva interdisciplinar da área parece acolher a proposta de pesquisar-se leitura e cognição com vistas a reunir, num mesmo conjunto, formulações de um e de outro campo, mas sem produzir um quadro teórico incongruente. Aqui, a suposição básica é que seja possível desenhar, a partir dessas diferentes fontes, um marco teórico consistente para a ciência da informação.

Todavia, do complexo de componentes da leitura, é necessário escolher 0 recorte que mais se aproxime do fazer científico do pesquisador. Do contrário, continuarão a circular as mesmas dificuldades e a serem relatadas todas as interferências possíveis, sem que se consiga galgar um novo patamar de entendimento do fenômeno. Dentre as áreas que trabalham com a informação, a ciência da informação possui a especificidade de buscar entender seu fluxo e - preocupação essencial como ela se manifesta em determinado indivíduo, segmento, grupo ou rede da sociedade. Isso significa refletir sobre os fenômenos que, nesse contexto, interferem na gênese, na organização e no uso da informação. 
Ao eleger-se o contexto, a subjetividade e o fazer sentido à leitura como recorte de pesquisa, o que se faz é tomar por balizas diretrizes primordiais da própria ciência da informação, cujo objetivo final não poderia ser outro senão produzir conhecimento.

Tais inquietações de estudo surgiram principalmente da atividade de fomento à leitura desenvolvida pelo trabalho de extensão do CarroBiblioteca da Escola de Ciência da Informação da UFMG. Desde 1973, esse programa atende, ininterruptamente, comunidades periféricas da região metropolitana de Belo Horizonte, incentivando o gosto pela leitura. Durante esse tempo, foi acumulado um bom volume de conhecimentos e experiências, gerados a partir de um contato próximo e diário com os usuários e seus contextos sociais.

Em dado momento, por exemplo, a experiência de incluir no acervo romances publicados em séries ${ }^{\mathrm{vi}}$ teve o objetivo de pesquisar sobre esse tipo de leitura e tecer novos conhecimentos sobre seus leitores e seus efeitos. A iniciativa recebeu, na ocasião, críticas diversas, por inserir obras de "valor duvidoso" em um programa que divulga o "bom" gosto pela leitura. Entretanto, no Carro-Biblioteca, acreditava-se que esses romances poderiam servir de atrativo para leitores que, a partir do contato também com outros tipos de publicações, buscariam uma experiência de leitura mais diversificada. No decorrer do tempo, isso foi efetivamente verificado, possibilitando o registro de casos com desenvolvimentos surpreendentes.

No momento, o Carro-Biblioteca entra em fase de também oferecer acesso à internet. Essa experiência de inclusão digital abre novas fronteiras de investigação, no que tange ao desafio de interagir com o usuário a partir das suas demandas reais, idiossincrasias individuais e práticas comunitárias. Também aqui, busca-se potencializar a aposta na exploração de novos caminhos de leitura, com base em vivências pessoais e contextuais cognitivamente relevantes.

A inserção social localiza essas iniciativas num campo em que se potencializa a descoberta de caminhos de significativa reconstrução de histórias de vida. Neste Brasil de exceções, uma narrativa inspiradora dessa percepção foi recentemente publicada em um periódico semanal (MOTA, 2008), focalizando as peripécias de Ubirajara Gomes da Silva, que exercitava sua cognição dentro do duro contexto que cabe a um morador de rua. Em busca de um futuro melhor, ele vinha estudando para o concurso do Banco do Brasil. Estudava como podia: sozinho, com amigos, pela internet... E passou!

As constatações possibilitadas pelas experiências do Carro-Biblioteca são fundamentais para o embasamento teórico da ação leitura, remetendo aos três motivos considerados propulsores da leitura e de sua verdadeira efetivação: o contexto do leitor, a sua subjetividade e o seu peculiar "fazer sentido" à leitura. Assim, se o leitor é capaz de fazer uma interpretação global do texto, e de finalmente perceber sentido nele, isso se dá por ser o próprio texto o fator que instiga a capacidade de interpretação e reflexão, propiciando uma leitura mais elaborada de situações dúbias ou "difíceis". A leitura é uma relação dialógica entre o 
mundo do texto e o mundo do leitor. Para que esse encontro se efetive, não é necessária apenas a competência técnica - indispensável, mas insuficiente. É preciso poder contar também com outra capacidade: saber integrar esses dois universos. Tal diálogo parece ser, até mesmo, a essência da integralidade da ação leitura, vista pela perspectiva da ciência da informação.

\section{A tela e o texto: rumo a um Brasil de leitores vii}

O Programa de Ensino, Pesquisa e Extensão $A$ tela e o texto ${ }^{\text {viii }}$ surgiu em 1998, na Faculdade de Letras da UFMG, das atividades de um grupo de estudos dedicado à literatura contemporânea e às trocas culturais na América Latina, que logo percebeu a necessidade da pesquisa aplicada. A análise crítica das teorias contemporâneas de leitura, com base na ideia de hipertexto, mostrava que a leitura do texto impresso associava-se à de imagens, em especial as que se movem nas telas do cinema, da televisão e do computador. Ademais, entre telas e textos - nas fronteiras de línguas/países ou de meios/linguagens - ocorrem trocas culturais assimétricas e conflituosas. Tais percepções contribuem para pensar as obras de arte, principalmente aquelas produzidas por palavras e imagens, como um território aberto, não-totalizável e passível de frequentes renovações.

Nasceu assim um espaço de leituras diversificadas, em que as teorias instigavam à produção do saber e de comportamentos democráticos. O compartilhamento de estudos e práticas levou, algumas vezes, a profundas divergências e rupturas internas, especialmente quando estavam em jogo questões éticas sobre o papel do intelectual na sociedade contemporânea, em relação a práticas individualistas, disciplinares e técnico-pragmáticas de produção e apropriação do saber. 0 grupo optou por uma perspectiva de inteligência coletiva que - conforme discute Lévy (1994) - traduz outra visão: as iniciativas de produção de saber e de sentido são estratégias compartilhadas e, por isso mesmo, frequentemente reorientadas, já que diferentes pontos de vista concorrem para sua existência. Decorre daí não um desaparecimento das disciplinas ou das competências individuais, mas a criação de novas possibilidades de cruzamento dos saberes, sob a forma de transdisciplinas que, inclusive, estabelecem espaços de aprendizagem para além da sala de aula tradicional.

No Programa $A$ tela e o texto, essa inteligência coletiva foi amplamente desenvolvida, a partir de três mecanismos básicos: a forma de organização do grupo, a combinação de protagonismo com instâncias de compartilhamento e o trabalho voluntário. Paulatinamente, os objetos de pesquisa - tais como textos e imagens - tornaram-se também instrumentos de intervenção social. Assim, aqueles primeiros movimentos geraram um Programa que hoje comemora 10 anos e contabiliza dezenas de projetos dedicados à formação do leitor contemporâneo. 
A partir de 2003, o Programa articulou ainda mais as dimensões de pesquisa com o ensino e a extensão, dedicando-se intensamente ao mais importante problema a ser resolvido pelas políticas públicas nacionais: o analfabetismo e o consequente iletramento de grande parte da população. Integrando da iniciação científica ao pós-doutorado, as pesquisas ativeram-se, para além da dependência econômica e cultural exógena, às causas históricas endógenas - escravidão, machismo, elitismo, oligarquismo etc. - que geraram o quadro de analfabetismo e exclusão cultural. Nossas elites dirigentes - políticas públicas, escolas, universidades, editoras etc. - foram mesquinhas na distribuição do capital cultural ao longo da história brasileira. Tal convicção é o motor de um intenso esforço para contribuir na reversão desse quadro, pela inovação das formas de mediação do acesso ao texto e à tela, com foco na população pobre. Essa concepção materializa-se em ações desenvolvidas hoje por uma dezena de projetos, no campo da leitura massiva, extensiva e intensiva. Vejamos alguns exemplos.

O Leitura para Todos disponibiliza lâminas com Literatura Brasileira nos ônibus da cidade, desde 2004, em parceria com a BHTRANS. Já propiciou a cerca de 400.000 leitores acesso a textos de escritores consagrados e jovens autores mineiros. Vencedor do Prêmio VilaLeitura 2007, o projeto inspirou ação semelhante por parte da CBTU, que inaugurou o Leitura no Metrô. O Bibliotecas Comunitárias Autogeridas disponibiliza na Internet um folheto com instruções para a criação desses equipamentos, oferece capacitação e realiza eventos culturais junto às comunidades parceiras. A Linha Editorial Tela e Texto publica, para venda a baixo custo, livros de bolso de Literatura Brasileira e livros teóricos que debatem a formação de leitores na sociedade da hipermídia, com a colaboração de escritores e pesquisadores do Brasil e do exterior, para subsidiar o letramento dos educadores e da população pobre. O Mostras e Estudos Audiovisuais promove mostras expositivas e competitivas de cinema e vídeo, no Brasil e no exterior, e oficinas de capacitação em produção audiovisual. Valoriza os realizadores locais e atende um público variado, dando acesso à produção de qualidade feita em Minas Gerais. O Fórum de Ensino de Leitura realiza debates sobre aspectos diversos dessa temática, contribuindo para a capacitação de um amplo público. A Revista txt - leituras transdisciplinares de telas e textos, associada ao projeto da Página Eletrônica, oferece artigos, entrevistas e outros textos sobre temas de interesse do educador contemporâneo. Projetos de cunho pedagógico, para formação de leitores - Letramento Literário Infanto-juvenil; Alfabetização, Letramento e Inclusão Digital; Capacitação de Educadores - ajudam a complementar o leque, abordando, de modo direto e articulado, educandos e educadores.

O vasto campo de mediações tecnológicas e simbólicas explorado nessa complexa rede impõe desafios diversos, referentes a financiamento, parcerias, gestão e voluntariado, dentre outros aspectos. Paulatinamente, o Programa vem desenvolvendo uma competência que lhe permite lidar com esses desafios e abrir caminhos que levem das ações locais mais 
específicas à possibilidade de influenciar a definição de políticas públicas, do nível regional ao nacional.

\section{Faz-se o caminho...}

As iniciativas anteriormente descritas envolvem formas diversas de mediação e uso da informação e do conhecimento, prestam direta atenção ao caráter social da ação desenvolvida e traduzem formas de relacionamento com a inovação tecnológica que condizem com a perspectiva de responsabilidade social da universidade. Todas elas apresentam dinâmicas compatíveis com o modo 2 de inovação apontado em nossa síntese gráfica, ilustrando práticas institucionais que exibem potencial para o estabelecimento de um ciclo virtuoso de demanda e produção de conhecimento e inovação de cunho socialmente relevante e responsável. Nessas práticas, o uso dos produtos da inovação tecnológica como instrumentos de mediação ocorre não com uma adesão celebratória - nos termos de Santos (2004b) - , mas como um movimento ativador de modos de apropriação que potencializam a reflexão crítica e estimulam a ação coletiva a articular-se em pressões contra-hegemônicas reorganizadoras das inter-relações entre as instâncias epistemológicas, políticas e produtivas.

Convém lembrar que, no modelo de Azevedo (2004), a dimensão cognitiva da produção de políticas públicas envolve dois aspectos: as relações do conhecimento científico com as representações sociais; as leituras possíveis dos problemas e soluções. Essa concepção reforça as pistas sobre a trilha a percorrer: o investimento de instâncias do meio acadêmico numa paulatina capacitação de parcelas antes excluídas da população, para que passem a demandar formas de inovação condizentes com o princípio de responsabilidade social. Mas tal perspectiva demanda dessas mesmas instâncias um preparo epistemológico e político que as afaste das visões paternalistas - inclusive as que o mercado alardeia como simulacro do princípio em pauta - e leve-as a buscar relações de corresponsabilidade com o meio social. Eis o rumo para a inovação da institucionalidade.

Há muitos percalços, porém. A pressão pela adesão da universidade à visão mercadológica de inovação é apenas parte de um movimento maior, que também se traduz na imposição dos pesados critérios quantitativos hoje vigentes na avaliação da produção acadêmica. 0 contexto criado por esses critérios implica dificuldades substanciais para o envolvimento com ações e projetos socialmente responsáveis. Nestes, a intensa dedicação exigida e os dilatados prazos de maturação necessários à geração de resultados são incompatíveis, via de regra, com o produtivismo em voga.

Essas dificuldades são ampliadas ainda mais pelo clima de concorrência acadêmica pessoal que se associa às imposições burocráticas. Nessas condições, a adoção de uma linha de trabalho compatível com a perspectiva de responsabilidade social requer do 
profissional atuante na universidade uma clareza política e um compromisso ético ainda maiores e em relação aos quais não é possível transigir. A atenção ao compromisso social que deve guiar a função pública é uma atitude fundamentalmente necessária, como contraponto à presença hegemônica da lógica de mercado e das dinâmicas institucionais que a ela correspondem.

Uma história que ilustra bem os desafios de compatibilizar responsabilidade social com produção acadêmica inovadora é a do neurocientista brasileiro Miguel Nicolelis. Dentre os percalços enfrentados em sua carreira, o pesquisador relata que teve de abandonar uma grande universidade brasileira, porque o caráter ousado do seu trabalho começou a encontrar mais resistências do que apoios. Acolhido pela Universidade de Duke, na Carolina do Norte (EUA), e desfrutando de um laboratório com as condições adequadas, ${ }^{\text {ix }}$ o brasileiro passou a produzir resultados que constituíram um novo marco na pesquisa sobre o funcionamento do cérebro e colocam-no hoje entre os 20 principais pesquisadores em atividade no mundo, segundo a revista Scientific American (NICOLELIS, 2007).

Além de assumir uma posição de destaque em sua área de investigação, Nicolelis demonstra também um admirável compromisso social, tendo fundando o Instituto Internacional de Neurociências de Natal, ${ }^{x}$ cuja inauguração deu-se em 2005. Reunindo em torno do projeto parceiros e patrocinadores diversos, ele optou por localizar a iniciativa em Macaíba, cidade pobre, com pouco mais de 60 mil habitantes, nos arredores da capital do Rio Grande do Norte. Além de abrigar um centro de pesquisa de padrão mundial, o instituto abre-se à comunidade local, oferecendo uma unidade de saúde, um centro educacional para crianças e adolescentes e diversas outras instalações e atividades ligadas ao universo da ciência e da cultura. Para o futuro, há planos de replicar o projeto em outras localidades do interior do país, para contribuir na diminuição das desigualdades regionais no campo da inclusão sociocultural e das oportunidades de formação científica (LOBO, 2006). Com esse projeto, Nicolelis e equipe manifestam sua confiança em relação ao futuro do Brasil exatamente contribuindo para a superação das perversas condições de exclusão estabelecidas no país.

O trabalho realizado em Macaíba encerra uma lição valiosa: conjugar pesquisa de ponta com projetos de legítima responsabilidade social é algo necessário para que a relação do mundo acadêmico com a inovação encontre caminhos que não levem à subserviência em relação à hegemonia capitalista. Essa não é uma visão assistencialista, e sim uma posição estratégica frente aos desafios de um jogo de poder de dimensões fabulosas. Numa perspectiva de longo prazo, condições aceitáveis de competição global somente poderão ser asseguradas, por países como o Brasil, mediante a atenção a um elemento que, quase paradoxalmente, conjuga fragilidades e potencialidades extremas. Esse elemento é exatamente o povo, cujas históricas condições de exclusão acusam um 
desperdício injustificável, perante os ganhos geralmente apropriados por minorias interessadas em realimentar essas mesmas perversas condições.

Se não está nas mãos da universidade o condão de reverter sozinha esse ciclo nada inovador "made in Brazil", também é certo que sua participação constitui um fator imprescindível e uma responsabilidade incontornável. A construção de formas inovadoras e mais eficazes de efetivar essa participação desafia o mundo acadêmico ao necessário esforço de abrir-se para fora. Esse é um tema que Nicolelis aborda de modo admiravelmente prático e que, de um ponto de vista teórico, Ribeiro (2003) discute com bastante propriedade, em articulação com outras questões importantes para a reflexão sobre a universidade no atual contexto da vida brasileira. Essa abertura deve se estender à pesquisa, mas também articular-se mais cuidadosamente com a extensão, a qual é preciso evitar que continue sendo enquadrada em meio a algumas categorias infelizmente bastante usuais: "apenas uma diluição do que se faz de melhor na pesquisa, sua tradução para o leigo, uma maneira de captar dinheiro" (p.64).

O tema extensão é particularmente caro à nossa discussão, e conjugá-lo à inovação pode parecer estranho a muitos. Entretanto, fugindo aos estereótipos mais comuns, os três projetos aqui focalizados buscam inserir a extensão em contextos com inegáveis possibilidades de inovação. Neles, podem ser desenvolvidas, por exemplo, diversas formas inovadoras de mediação, capazes de gerar condições para uma apropriação mais potente e integrada, pelo público atendido, dos meios tecnológicos e das capacidades cognitivas e organizativas que constituem pressupostos de qualquer perspectiva legítima de inclusão social, cultural e digital. Projetos de semelhante caráter ajudam a reverter, em certa medida, um erro cometido com frequência dentro e fora dos campi universtários: "não transmitir aos cidadãos a noção desse papel social da pesquisa, do ensino, da formação" (RIBEIRO, 2003, p. 65). Além disso, na mediação das relações entre o dentro e o fora do espaço acadêmico, eles podem também contribuir para a construção de uma perspectiva de aprendizagem institucional que surge com a noção de ecologia dos saberes, segundo a proposta de Santos (2005): o respeito pelos saberes locais pode se materializar num movimento de "extensão ao contrário" de efeitos inovadores para as relações entre univers(al)idade e localidade.

Mas não deve haver exagero nas pretensões e expectativas. Também esses projetos ficam sujeitos à marcante contradição entre as potencialidades significativas de inovação que guardam e as exíguas condições institucionais disponíveis para 0 seu desenvolvimento. A presença comparativamente ainda pouco expressiva de ações e programas sobre tecnologias sociais nos diversos níveis institucionais da universidade é uma expressão dessa realidade. A leitura atenta do discurso que circula majoritariamente nesse âmbito faz perceber que as discussões sobre tecnologia e inovação ainda são pautadas pelo mercado.

Muitas iniciativas "da universidade" ligadas ao universo das demandas sociais são ainda fruto de articulações de pequenos coletivos ou 
decorrem de esforços individuais de alguns poucos que ainda conseguem atuar guiados por motivações e opções distoantes das tendências hegemônicas. Existe, assim, uma imensa distância entre as responsabilidades individuais e coletivas manifestadas nessas ações e a responsabilidade institucional que a universidade é chamada a assumir. No campo em que se articulam leitura, informação e comunicação, esses contrastes são especialmente desafiadores, uma vez que perspectivas como a da inclusão digital implicam o resgate de uma dívida social historicamente construída, referente às outras formas de inclusão tradicionalmente negadas à maioria dos brasileiros.

Ao insistirem no esforço de efetivar iniciativas como as que destacamos, alguns atores locais chamam a universidade a mover-se para outro lugar, distante dos sorrisos fartos e marotos do deus-mercado. Nesse lugar, que só tem espaço nas utopias contra-hegemônicas, fica mais nítida uma visão: se há uma forma de inovação na qual o Brasil deve investir com urgência cada vez maior, são as ações diversas de inclusão social. E assim como o gato de Alice adverte sobre que é preciso saber aonde se quer ir para escolher o caminho, os protagonistas desse contramovimento - ainda que sem tantos sorrisos fáceis, em meio ao ardor da luta que travam - seguem abrindo picadas, desbravando terrenos. Mesmo que os parceiros costumem ser poucos, eles sabem que a qualidade do engajamento bem pode ajudar a suprir a falta. Aos que se propõem os desafios da representatividade, não se cansam de reiterar o convite.

Diante dos ares quixotescos da empreitada, convém lembrar, a modo de alento: o pensamento complexo aponta o grande potencial das dinâmicas de realimentação, inclusive no contexto social, para produzir novos processos de ordenamento e estabelecer novas condições macroambientais. Difíceis e lentos como pareçam os primeiros passos nessa trilha, os rumos futuros podem surpreender, quando os mecanismos sociais de realimentação cognitiva, epistemológica e política alcancem suficientes níveis de estabilidade. É instigante o resumo da lição: mesmo ainda turvo, o horizonte é amplo. Mas o caminho se faz ao caminhar...

\section{Referências}

AZEVEDO, J.M.L. A educação como política pública. 3. ed. São Paulo: Autores Associados, 2004.

BELKIN, N.J. The cognitive viewpoint in information science. Journal of Information Science: Principles \& Practice, London, v. 16, n. 1, p. 11-16, 1990. (Número dedicado aos 80 anos de B.C. Brookes).

BOAL, A. O mercantilismo é o fim da arte. Extra-Classe Online, Porto Alegre, ano 4, n. 4, ago. 1999. Entrevista concedida a César Fraga. Disponível em: <www.sinpro-rs.org.br/extra/ago99/entrevista.htm>. Acesso em 20 ago. 2009. 
BOAL, A. Teatro do Oprimido e outras poéticas políticas. Rio de Janeiro: Civilização Brasileira, 1975. 222 p.

BORGES, M.E.N. et al. Estudos cognitivos em ciência da informação. Encontros Bibli: Revista Eletrônica em Biblioteconomia e Ciência da Informação, Florianópolis, v. 8, n. 15, jan./jun. 2003. Disponível em: <www.periodicos.ufsc.br/index.php/eb/article/view/116/5232>. Acesso em: 02 abr. 2009.

CHAUI, M. A universidade pública sob nova perspectiva. Revista Brasileira de Educação, Campinas, n. 24, p. 5-15, set./dez. 2003.

CUNHA, A.A.; SANTOS, M. O. BH-Tec e o aprendizado da inovação. UFMG Diversa; Revista da Universidade Federal de Minas Gerais, Belo Horizonte, ano 8, n. 17, ago. 2009. Disponível em: <www.ufmg.br/diversa/17/>. Acesso em: 27 ago. 2009.

DUMONT, L.M.M. O imaginário feminino e a opção pela leitura de romances de séries. 1998. 257 f. Tese (Doutorado em Ciência da Informação) - IBICT/ECO-UFRJ, Rio de Janeiro, 1998.

FREIRE, P. Extensão ou comunicação? 10. ed. São Paulo: Paz e Terra, 1988.

GARDNER, H. A nova ciência da mente: uma história da revolução cognitiva. São Paulo: Ed. Universidade de São Paulo, 1996.

HIGINO, A.F.F.; SANTOS, C.B.; PEREIRA, M.A. (Org.). Formando leitores de telas e textos. Belo Horizonte: Linha Editorial Tela e Texto, FALE/UFMG, 2007.

HIGINO, A.F.F.; ARAÚJO, R.F.; SCOTT, C.S.P. Construção de políticas de informação: aspectos epistemológicos e metodológicos. Liinc em Revista Online, v. 4, n. 2, p. 286-302, set. 2008. Disponível em: <http://revista.ibict.br/liinc/index.php/liinc/article/viewFile/283/176>.

Acesso em: 15 jan. 2009.

LAMBERT, J. A mídia ao lado dos "sem-voz". Boletim Informativo da Universidade Federal de Minas Gerais, Belo Horizonte, ano 32, n. 1529, 04 maio 2006. Entrevista concedida a Kleyson Barbosa e Sílvia Dalben.

LÉVY, P. A inteligência coletiva: por uma antropologia do ciberespaço. São Paulo: Edições Loyola, 1994.

LOBO, F. Brasileiro voador. CartaCapital, São Paulo, ano 12, n. 376, p. 817, 18 jan. 2006.

MANCEBO, Deise. Reforma universitária: reflexões sobre a privatização e mercantilização do conhecimento. Educação \& Sociedade, Campinas, v. 25, n. 88, p. 846-866, out. 2004.

MARTÍN-BARBERO, J. Dos meios às mediações: comunicação, cultura e hegemonia. Rio de Janeiro: Editora UFRJ, 1997.

MOTA, U. Ubirajara calcula. CartaCapital, São Paulo, ano 14, n. 506, p. 67, 30 jul. 2008. 
NICOLELIS, M. Vendedor de sonhos. CartaCapital, São Paulo, ano 13, n. 427, p. 26-31, 17 jan. 2007. Entrevista concedida a Mauricio Dias, Mino Carta e Rodrigo Martins.

PEREIRA, M.A. Para ler o texto e o grupo: rizoma, árvore e rede. In: RICARDO, A. C. et. al. (Org.). Na trama da rede social. Belo Horizonte: Faculdade de Letras da UFMG, 2007. p. 21-36.

PEREIRA, M.A. Um balanço da aplicabilidade das teorias de rede. In: PEREIRA, M.A. et. al. (Org.). Dez anos formando leitores: literatura, política e teorias de rede. Belo Horizonte: Faculdade de Letras da UFMG, Linha Editorial Tela e Texto, 2008. p. 11-23.

REIS, A.S.; MOURA, M.A.; RIBAS, C.S.C. Oralidade, mediações e digital storytelling: potencialidades e a afirmação das narrativas do sujeito. In: ENCONTRO NACIONAL DE PESQUISA EM CIÊNCIA DA INFORMAÇÃO: Promovendo a inserção internacional da pesquisa brasileira em Ciência da Informação, 8., 2007, Salvador. Anais... Salvador: PPGCI/UFBA, 2007. 1 CD-ROM.

RIBEIRO, R.J. Fellini não via filmes. In: $A$ Universidade e a vida atual: Fellini não via filmes. 2. ed. Rio de Janeiro: Campus, 2003. p. 56-69.

SANTAELLA, L. Cultura das mídias. São Paulo: Experimento, 1996.

SANTOS, B.S. A justiça social vai obrigar a que se comprometa com a justiça cognitiva. UFMG Diversa; Revista da Universidade Federal de Minas Gerais, Belo Horizonte, ano 3, n. 8, out. 2005. Entrevista. Disponível em: <www.ufmg.br/diversa/8/entrevista.htm>. Acesso em: 30 ago. 2009.

SANTOS, B.S. A universidade no século XXI: para uma reforma democrática e emancipatória da universidade. São Paulo: Cortez, 2004a.

SANTOS, B.S. Para uma sociologia das ausências e uma sociologia das emergências. In: (Org.). Conhecimento prudente para uma vida decente: um discurso sobre as ciências revisitado. São Paulo: Editora Cortez, 2004b. p. 777-821.

UFMG. UFMG Diversa; Revista da Universidade Federal de Minas Gerais, Belo Horizonte, ano 5, n. 10, out. 2006. Disponível em: <www.ufmg.br/diversa/10/>. Acesso em: 30 maio 2009.

\footnotetext{
iii Alcenir Reis />. Acesso em: 30 a go. 2009.

iv Alcenir Reis agradece à Profa. Maria Aparecida Moura, às suas orientandas Claudia S. da Cunha Ribas e Ana Paula Pedroso, bem como a Leonardo Renault, pela participação e colaboração nas oficinas de Storytelling.

${ }^{\vee}$ Endereço eletrônico: <www.storycenter.org>. Acesso em: 30 ago. 2009.

vi Publicações de bolso vendidas em bancas de revista. As séries mais conhecidas são Júlia, Bianca e Sabrina.

vii O relato de Maria Antonieta Pereira é baseado no capítulo "Um balanço da aplicabilidade das teorias de rede", do livro Dez anos formando leitores: literatura, política e teorias de rede (PEREIRA, 2008).

viii Endereço eletrônico: <www.letras.ufmg.br/atelaeotexto>. Acesso em: 30 ago. 2009.
} 
Mediaçao informacional no contexto universidade-sociedadeinovação: pontecialidades,contradições e desafios
Andeson Fabian Ferreira Higino; Alcenir Soares dos Reis; Lígia Maria Moreira Dumont; Maria Antonieta Pereira

ix Endereço eletrônico: <www.nicolelislab.net/>. Acesso em: 30 ago. 2009.

x Endereço eletrônico: <www.natalneuro.org.br>. Acesso em: 30 ago. 2009. 